\title{
'The right kind of person for the job'? Emotional labour and organizational professionalism in probation
}

\begin{abstract}
This paper utilises the concept of organizational professionalism to illustrate the importance of emotional labour for probation practice, as well as its potential consequences for practitioners. Based on an ethnographic study of a probation office led by a privately-owned Community Rehabilitation Company (CRC), the paper demonstrates that probation values are operationalised through the performance of emotional labour with offenders. However, the implementation of the Transforming Rehabilitation (TR) reforms has exacerbated long-term trends away from working with 'people' towards working with 'things' - that is, the information technologies on which the CRC depends for payment. That practitioners are willing to forgo their administrative responsibilities to spend time with their clients suggests emotional labour is fundamental to practitioner understandings of professional identity. The paper thus demonstrates that the challenges of balancing a client-centred ideology of service with the increased administrative pressures that have accompanied the $T R$ reforms have further exposed probation practitioners to emotional exhaustion, stress, and sickness.
\end{abstract}

Key words: Probation; Transforming Rehabilitation; Emotional Labour; Organizational Professionalism

\subsection{Introduction}

The Transforming Rehabilitation (TR) reforms represent a radical restructuring of probation services in England and Wales. The Coalition government asserted that a targetcentric culture of state intervention had become entrenched within probation under previous New Labour administrations, inhibiting professional discretion and contributing to increases in the prison population (MoJ, 2010, 2013a). Appeals to a discourse of 'professionalism' proved crucial to the Coalition government's rationalisation of organizational change (MoJ, 2010, 2013a). Creating markets for low-to-medium risk offenders for private and voluntary organizations, they argued, would "put trust in frontline professionals who work with offenders and...free them from bureaucracy" (MoJ, 2013a: 13). As such, from June $1^{\text {st }} 2014, T R$ split the probation service into two types of organization: the publicly-owned National Probation 
Service (NPS) manages offenders deemed to pose a high risk of harm to the public, while 21 privately-owned Community Rehabilitation Companies (CRCs) supervise low-to-medium risk offenders (NAO, 2016).

Despite the Coalition government's claims as to the enhanced 'efficiency' and 'effectiveness' that would result from privately-led probation services (MoJ, 2013a), quasigovernmental inspectorates have consistently reported on the financial challenges faced by CRCs and how they are linked to their underperformance (NAO, 2019; HMI Probation, 2019). As such, a deterioration in working conditions in the CRCs (Kirton and Guillaume, 2015), including 'unmanageable' workloads for 56\% of staff (HMI Probation, 2019: 74), has contributed to an increase in levels of sickness (HMI Probation, 2017; Walker et al., 2019). However, research also indicates that the $T R$ reforms have not resulted in substantive changes to working identities and culture, as probation staff have retained a determination to prioritise offenders (Robinson et al., 2016; Burke et al., 2017).

This paper explores the importance of emotional labour for professional identity for probation practitioners working in a CRC. It attempts to make sense of probation work before and after the implementation of $T R$ through the lens of organizational professionalism (Evetts, 2013) - which states that, while managerial and, latterly, marketising reforms have partially reduced autonomy over work, professionals continue to be committed to their clients. The first part outlines the study's aims and methodological approach. The second part utilises organizational professionalism to show how, against the backdrop of sustained challenges to practitioner autonomy in recent decades (e.g. Phillips, 2011; Mawby and Worrall, 2013), and especially since $T R$ was implemented, people-oriented probation values have proved resilient to organizational change (Burke et al., 2017). The third part demonstrates how these ideals are exercised through the performance of 'emotional labour', or the ability to draw "on a source of self that we honor as deep and integral to our individuality" (Hochschild, 2012: 7). TR has, however, amplified long-term trends towards engagement with 'things' (i.e. information technologies) over 'people' (Hochschild, 2012). The fourth part shows how the difficulties of balancing people-work with administrative work can contribute to high levels of sickness in probation - evidenced by a case study of 'Will', who was absent from work for two and a half months due to the strains of the job. Paradoxically, therefore, enacting the people-oriented values which make a person 'right' for probation can also expose them to stress, sickness, and emotional exhaustion. 


\subsection{Methodology}

The research explored how probation staff have experienced the $T R$ reforms, with specific regard to culture, practice, and understandings of professionalism. Data were generated via ethnographic study of 'Elizabeth Street', a pseudonym for a privately-owned CRC office in a large city in England. A private provider was selected for study because CRCs can be considered the sites of the most significant organizational change (Deering and Feilzer, 2015). Amongst the apprehensions over the $T R$ reforms was the potential impact of the profit-motive on probation's culture and values (e.g. McNeill, 2013), a concern supported by research on the transition from public to private employment. For example, Robinson et al. (2016: 173) used the concept of 'liminality' - that is, "the experience of being betwixt and between the old and the new" (emphasis in original) - to show how probation staff adapting to a newly established CRC felt a sense of status anxiety and loss of identity.

Access to a CRC was informally obtained following contact with a 'gatekeeper' (a research officer employed by the parent company that leads Elizabeth Street) and approved by the board of directors, before being formally granted by HM Prison and Probation Service's (HMPPS) National Research Committee. I observed everyday life at Elizabeth Street for three to four days per week over a period of six months (April-October 2018), and was present for approximately seven hours per day. As such, I carried out unstructured observations on a range of activities (supervision meetings with offenders, unpaid work, team meetings, multi-agency meetings, etc.), which facilitated identification of potential informants for interview as well as refining the themes to be explored. Sixty-one observations were conducted, of which 47 were between a single offender and their supervising practitioner. Data were recorded by hand and typed up on a computer when I returned to the desk that I had been assigned.

In addition, staff with varying experience in probation, from six months to four decades, were selected for a one-hour interview. I conducted 20 semi-structured interviews, comprised of ten probation service officers (PSOs), five probation officers (POs), three senior probation officers (SPOs), and two Senior Managers. The sample broadly reflected the demography of the office, and of probation in general, in that $70 \%$ of interviewees were female (Deering and Feilzer, 2015). However, the gender composition of staff grades will not be disclosed so as to safeguard participants' anonymity. The names presented below are pseudonyms, all of which were selected by the researcher. Interviews were conducted in private and digitally recorded, before being transcribed verbatim. Data derived from both observations and interviews were sorted, thematically coded, and analysed using NVivo. The small-scale nature of the study 
means that the findings are not generalisable to other CRCs. But this admission should not be read as a weakness of ethnographic methodology; rather, a focus on a single site provides rich insight in one (probation) locality (Hammersley and Atkinson, 2007).

\subsection{Probation and organizational professionalism}

'Professionalism' is a contested concept that has undergone considerable change; indeed, most scholars no longer view definitional exactitude as integral to its study (Evetts, 2013). Where early functionalist perspectives emphasised the normative importance of 'professionalism' as a value system defined by a client-centred ideology of service (e.g. CarrSaunders and Wilson, 1933), later neo-Weberian interpretations stressed its ideological worth as a project of occupational closure concerned with maintaining autonomy over work (e.g. Freidson, 1970). Such contestation is seldom acknowledged within a probation context, although May and Annison (1998) provide a notable exception to this neglect. They draw upon the sociology of the professions literature to argue that 'professionalism', as it pertains to probation, "has moved from a voluntary-evangelical phase (up to 1925), through a professional-therapeutic phase (up to the 1970s) to a punishment-administrative phase" (see also McWilliams, 1983, 1985, 1987). This is to say that the service's claim to professional status was rooted in a functionalist ideology of service that emerged in the voluntaryevangelical phase: the words 'advise, assist and befriend' inscribed within the Probation of Offenders Act 1907 acted as "a kind of moral shorthand" (Nellis, 1995: 19) for the service's values (May and Annison, 1998). The shift towards social work knowledge during the professional-therapeutic phase built upon such values, while state support for probation's methods granted practitioners significant autonomy over work (May and Annison, 1998).

With the collapse of the rehabilitative ideal in the 1970s, however, the tenets on which the service's professional claims were predicated were subject to critical scrutiny (May and Annison, 1998). Rising postwar crime rates and the 'Nothing Works' (Martinson, 1974) scepticism of the 1970s converged to challenge the socio-economic worth of pursuing offender rehabilitation (May and Annison, 1998). Critique of autonomous probation practitioners and their tolerance of inconsistent practice (Cohen, 1985) thereby resonated with emergent neoWeberian understandings of 'professionalism' that constructed professionals as self-interested (Freidson, 1970). The rise of managerial discourses in the 1980s sought to replace abstract public service ideals with measurable objectives that regulated organizational practices, as the service entered a punishment-administrative phase (McWilliams, 1987; May and Annison, 
1998). Accountability came to be expressed via adherence to performance targets, while the introduction of National Standards from 1992 onwards imposed prescriptive guidelines upon practice that constrained practitioner autonomy (Phillips, 2011). In this climate, generic social work values lacked contemporary relevance for probation (Nellis, 1995). For Kemshall and Wood (2007: 386), the constitution of probation as a sentence in its own right; an influx of offenders deemed to be high-risk to the public onto the service's caseload, including those convicted of sexual offences; and a greater emphasis on partnership working with prisons and the police contributed to the service's shift "from a predominantly welfare orientation to a riskbased one." Indeed, the abolition of social work training requirements for practice in 1995 exemplifies how professionalism in probation has been reshaped by demands for a service that was at once punitive and efficient (May and Annison, 1998).

These attempts to revise professionalism in probation are concurrent with Evetts's (2013) notion of organizational professionalism, which overlays the functionalist emphasis on an ideology of service with the neo-Weberian stress on autonomy over work, although such control is transposed onto managers. This is to say that many occupations, particularly in the public sector, are subject to greater political and managerial control; however, professionals "are expected to and expect themselves to be committed, even to be morally involved in the work. Hence, managers in organizations can use the discourse of professionalism to selfmotivate, inner-direct and sometimes even exploit professionals" (Evetts, 2013: 787). Fournier (1999) argues that professionalism can be deployed to regulate occupations and to rationalise organizational change by inscribing 'appropriate' work identities and practices within staff. In this Foucauldian sense, workers' conduct becomes self-adjusting, as professionalism has been extended as a disciplinary logic that serves to regulate workplace behaviour 'at a distance' via appeals to 'professional' conduct (Fournier, 1999: 281; Evetts, 2013).

At the macro-level, the Coalition government's claims as to the market's ability to enhance 'professionalism' were crucial to attempts to justify organizational change (Evetts, 2013). The logic of competition and profit, they argued, was necessary for the restoration of 'professionalism', which was most clearly expressed through the increase in autonomy that would result from a relaxation of National Standards and the removal of centrally-administered performance targets (MoJ, 2010, 2013a). The Coalition government's critique of previous New Labour administrations' "Whitehall knows best" (MoJ, 2010: 6) approach laid the foundations for TR (MoJ, 2013a). And yet, this managerial philosophy was perpetuated in their imposition of reforms which promised greater discretion whilst depriving staff and trade unions of meaningful consultation (Deering and Feilzer, 2015). 
However, key legislative changes have undermined micro-level attempts to improve autonomy over work since TR. For example, CRCs are paid via a 'Payment by Results' (PbR) mechanism comprised of three elements: 'fee for service', an output-based payment for the delivery of statutory services; 'fee for use', for services delivered on behalf of the NPS; and 'payment by results', the outcome-based measure linked to reductions in reoffending (NAO, 2016). And yet, CRCs' funding is heavily weighted in favour of 'fee for service': private providers' were hesitant about assuming the risks to cashflow associated with an over focus on outcome-based 'payment by results' (NAO, 2019), while the NPS's reluctance to commission services from CRCs because of concerns over value for money have negatively impacted 'fee for use' payments (HMI Probation, 2018). Further, the extension of "statutory rehabilitation" (MoJ, 2013a: 6) to all offenders who serve over one day in custody has added approximately 45,000 offenders onto the total caseload (NAO, 2016). Though CRCs' business volumes have been lower than anticipated (NAO, 2016), staff redundancies have increased individual workloads (HMI Probation, 2019). As Dame Glenys Stacey, the former Chief Inspector of HMI Probation, has observed, this combination of financial hardship and caseload pressures has entrenched a focus on 'fee for service':

[CRCs] are running with ever fewer professional staff and taking other steps to contain or manage expenditure - and to reduce it, wherever possible. They are pared back...and focus predominantly and understandably on what is measured and what is rewarded. (House of Commons Justice Committee 2017: 3)

And yet, empirical research has shown that a desire to work with people underpins working identities in probation (Annison et al., 2008; Mawby and Worrall, 2013). Concurrent with organizational professionalism, probation staff make sense of their work through adherence to a relatively homogeneous value set which is inclusive of non-judgemental attitudes towards offending, a belief in offenders' capacity to change, and recognition of sociostructural disadvantage as a determinant of offending behaviour (Deering, 2010; Deering and Feilzer, 2015). When TR was announced, there were concerns over the impact of competition and profit on the preservation of probation values (e.g. McNeill, 2013; Deering and Feilzer, 2015). The Coalition government acknowledged such dissonance: "staff members were generally opposed to the policy of opening up to competition the management of offenders and believed that this should be a function directly provided by public servants" (MoJ, 2013b: 5). However, ethnographic studies of staff shifted to a CRC have demonstrated their continued 
commitment to a probation ethos in which offenders were prioritised (Robinson et al., 2016; Burke et al., 2017).

The residue of humanitarian endeavour, therefore, persists within probation - although it is operationalised on a transformed landscape in which $T R$ has intensified, if not initiated, the pressures of work. Given the obligations practitioners feel towards offenders, the next section considers 'emotional labour' (Hochschild, 2012) to be integral to enacting probation values, and thus the realisation of organizational professionalism. The data presented below reflect the preference of informants to describe the recipients of services as 'clients' (or, occasionally, 'service users') over 'offenders'.

\subsection{Probation work as emotional labour}

Emotions are responses to particular stimuli that communicate information; in this way, they shape and are shaped by interactions (Morris and Feldman, 1996). Hochschild (2012: 7) defines emotional labour as a requirement "to induce or suppress feeling in order to sustain the outward countenance that produces the proper state of mind in others." Despite material differences in the organization of work, she identified common ground between the labour of a child in a nineteenth century English factory and a flight attendant in 1980s America. The shift from working with 'things' to working with 'people' gave rise to new forms of labour that depended not upon workers' somatic functions, but upon the commercialisation of their feelings and emotions (Hochschild, 2012: 9). Both the child labourer and the flight attendant must detach themselves from the aspects of the self upon which their jobs are dependent. Where the former must separate himself from his body, the latter must dissociate herself from her emotions. In this sense, Hochschild (2012) draws upon the Marxist concept of alienation to explore how post-industrial labour is similarly commodified and how it impacts workers. She argues that emotional alienation manifests in two distinct ways: 'emotive dissonance' results from 'surface acting', as the worker must contrive emotions different from their true feelings when dealing with clients; emotional exhaustion, by contrast, is a consequence of 'deep acting', as workers attempt to convince themselves that feelings are real (Hochschild, 2012: 33).

Emotional labour has provided a framework within which to conceptualise how employees working in client-facing organizations regulate their conduct (Morris and Feldman, 1996). Probation is one such arena in which emotional labour is prominent (Phillips et al., 2016; Westaby et al., 2016). For example, Phillips et al. (2016: 183) have demonstrated the 'relentless' nature of engaging exclusively with high-risk clients for staff in the NPS. By 
managing their own emotions, whether engendering enthusiasm or repressing revulsion, probation staff seek to influence their clients' behaviour to work towards a 'proper state of mind" (Hochschild, 2012: 7) - that is, to desist from crime (Maruna, 2001). Unlike Hochschild's (2012) conception of emotional labour, however, interpersonal work in probation is not explicitly commodified. The nature of working with "involuntary clients" (Trotter, 2014: 3) means that staff are not instruments of labour on which the CRC depend to attract offenders' repeat custom, nor is there an "emotion supervisor immediately on hand" (Hochschild, 2012: 153 ) to regulate conduct. That said, CRCs, as contract holders, rely upon practitioner conduct with their clients as part of their appeal to commissioning bodies such as HMPPS - not least because the "[p]ercentage of offender surveys that demonstrate a positive experience" (HMI Probation, 2017: 40) is one of the metrics by which performance is assessed.

Training is one such way in which an organization can convey its expectations of appropriate conduct to staff (Hochschild, 2012). Marie, a PSO who joined the service after TR was implemented, reflected on her experience of training:

...the biggest part of the training was how to deal with people, not being confrontational, breaking down the barriers - that was very easy. I think you can either do that or you can't.

This shows how appropriate display of emotion is both habitual and imposed, derived from probation values which prioritise the client (Deering, 2010; Burke et al., 2017) on the one hand and organizational display rules on the other. Staff are educated in how to behave with clients, but also possess an intuitive feel for 'breaking down the barriers' which draws from a sense of self that is integral to practitioners' individuality (Hochschild, 2012). Marie, however, added that a focus on performance has impinged upon the amount of time she is able to dedicate to clients:

In some ways, I probably thought that the service users would be more difficult than they have been. In reality, the hardest part of the job is the targets and recording of stuff - a far, far bigger part of the job, which does bother me because the amount of time you spend doing that means that you lose that time face-to-face.

Accordingly, counter to Hochschild's (2012) observations on the nature of post-industrial work, and the Coalition government's pledge to "minimise bureaucracy" (MoJ, 2013a: 24), 
probation practice under $T R$ has continued to move towards working with 'things' over 'people'.

\subsubsection{From working with 'people' to working with 'things'?}

As argued above, research has consistently demonstrated that practitioners are attracted to a career in probation because of a desire to work with people (Knight, 2007; Annison et al., 2008; Deering, 2010). Indeed, staff at Elizabeth Street expressed similar motivations for joining the service:

...it was the nurturing element of...the job...spending a lot of time with certain individuals with complex or chaotic lifestyles to have an impact, a positive influence on their life. (Trudy, PSO)

Helping to engender change within individuals underpins professional identity at Elizabeth Street, enabling staff to make sense of their role:

I would say there's a common belief in terms of...helping somebody turn their life around, etc. I think that belief is pretty fundamental, and I think that people here would share that belief. (George, PO)

That staff at Elizabeth Street whose experience varies from 24 years (Kate) to nine months (Marie) shared mutual understandings of probation values further indicates their persistence through major organizational change (see also Robinson et al., 2016; Burke et al., 2017):

Probation...values are about not judging people, believing that people can change, accepting that people behave in certain ways because of social or psychological circumstances. (Kate, SPO)

I think that the organization is pinned on values...[such as]...not being judgemental, being empathic [sic], being understanding, but also [having] sympathy with the victims. (Marie, PSO) 
Ashley (Senior Manager) linked people-oriented values to practitioner perceptions of probation as a 'vocation' (Mawby and Worrall, 2013), which encourages staff to give more of themselves to the role:

I would say that the majority of people I know who come into this job see it as a vocation...which is why you work harder...I think people come in with those values around fairness, equity, responsibility, rights, and supporting people through all those things.

Ashley's view resonates with Evetts's (2013) notion of organizational professionalism: an increase in individual workloads as a result of $T R$ can be offset by values that self-motivate staff to 'work harder'. This suggests that probation practice reflects a third form of emotional labour, 'genuine expression', in which “the worker actually feels the emotion that is required or expected" (Kadowaki, 2015: 328).

People-oriented values are, in Will's (PSO) terms, what makes somebody 'the right kind of person for the job':

I think that you've got to have certain values to be...the right kind of person for the job. Being able to sort of assist people in that sense, to assist them to identify the problems in their own lives; and then, beyond that, to want to make some positive changes, to see that change is possible.

An eagerness to work with clients and to establish relationships is integral to practitioners' sense of self (Knight, 2007; Deering and Feilzer, 2015):

You have to have a level of interpersonal skills; you have to be made for the role. Sometimes, I don't know how certain people get this role. (Mo, PSO; my emphasis)

Expanding on her comment, Mo recalled an experience with a client who felt that his previous practitioner was not 'made for the role':

As an example, I'll give you what a service user's complained to me about. He's been a drug user since he was 16: he uses heroin and crack on a regular basis. His officer was quite young, spoke quite well, and she just could not relate. He said, 'I don't want 
to talk to a young girl who's got no clue about life, who...thinks I can just come off heroin'. I think he was trying to compare the way she was [with] the way he was...So, it's a hard job when you meet people like that; you have to speak to them in a way they understand and communicate with them in a way that they understand.

This example highlights how 'feelings rules' (Hochschild, 2012: 18) govern exchanges in probation, as practitioners must demonstrate to clients 'that they understand'. Accordingly, the ability to empathise with clients, to identify with their feelings, attitudes, and emotions, can be considered a crucial aspect of practitioner understandings of professionalism:

I think that one of our core values is to be professional at all times and I think that...we're expected to display that at all times. I think that I would display it in the relevant circumstance. (Vicky, PSO)

This hints at an intuitive feel for, and the ability to convey, behaviours that are 'appropriate' (Fournier, 1999; Kadowaki, 2015). In this Foucauldian sense, an ingrained commitment to 'doing the right thing' for clients allows for discipline 'at a distance' (Fournier, 1999), as staff demand a certain quality of service of themselves:

The basics of professionalism, for me, are adhering to policies, making sure that...you're dealing with other agencies and service users, the way you communicate is appropriate to them; it's about having integrity, doing the right thing. Quite a lot, we're not monitored by anybody, so it's down to us to do what's right. (Maddie, PO)

Like the guardians in Burke et al.'s (2017: 200) study, who retained a probation ethos but were determined to adopt a 'business as usual' approach to the reforms, Louise (SPO) highlighted how practitioners' caring approach to working with clients has helped them (and the $\mathrm{CRC}$ ) to negotiate organizational change:

I think to do your job thoroughly and spend as much time as you can and do the assessments properly with the clients is a tough thing to do. I think we achieve that, in most cases, but that's the challenge: deciding what the focus of your work is and making sure that you can do the best job that you can do. I think we're lucky that we have a lot of people who care a lot and want to do meaningful work. 
Concurrent with organizational professionalism (Evetts, 2013), then, probation values can act as a resource with which practitioners can offset managerial changes and find meaning in their work.

And yet, administrative responsibilities at Elizabeth Street have been intensified since the implementation of $T R$. Where other CRCs have made frontline practitioners redundant (HMI Probation, 2019), no such job losses were imposed by the parent company that leads Elizabeth Street. However, their decision to make administrative staff redundancies has negatively impacted practitioners' workloads, thereby amplifying their engagement with information technologies (Tidmarsh, 2019):

I cannot stress how much we miss our admin and the impact that's had on our workload because we're doing all the admin. (Rhonda, PSO)

This is not to say that the trend towards working with 'things' is unique to $T R$, for a wealth of probation literature has explored the growing importance of information technologies to probation practice in recent decades (e.g. Robinson, 2003; Annison et al., 2008; Phillips, 2011). Rather, mirroring the national picture (HMI Probation, 2017, 2019), practitioners at Elizabeth Street asserted that $T R$ has exacerbated long-term trends away from working with 'people':

I get here and I normally have about 45 missed calls from 5pm that I've not been in to deal with. Then I've got loads of emails, so I'll probably do that for at least a couple of hours. Then I need to check enforcement and my alerts to see if I've got any new cases... or if any of my current cases are in court or have been recalled...I spend all day behind the computer updating things... doing referrals to other agencies, chasing around my clients. (Matilda, PO)

On the surface, this appears to suggest that the regularity with which practitioners are able to perform emotional labour, to engage with 'people', has diminished. And yet, as Matilda's comment indicates, considerable time is spent on the telephone checking up on the whereabouts of their clients. The 'frequency of appropriate emotional display' (Morris and Feldman, 1996: 989) has thus been partially displaced from face-to-face onto voice-to-voice interaction, mediated by information technologies. Indeed, HMI Probation (2017) have expressed concern at the manner in which telephone supervision now accounts for 
approximately $40 \%$ of 'meetings' within CRCs. While this mode of supervision is not pursued at Elizabeth Street, telephones nonetheless prove useful for practitioners when reminding clients of their legal obligations to attend the office in ways that avoid conflict:

Camilla's 11am supervision did not attend, but I overheard her on the phone to him shortly after. She struck a humorous tone: 'I never want to see you again when we get to the end of your order! But you have to come and see me next week or I'll have to breach you, okay?' Camilla later informed me that he had probably been put off by the rain; but she was happy to accept it and reschedule the appointment to avoid a breach. (notes from fieldwork)

Camilla's caustic reprimand typifies how practitioners manage their own and their clients' emotions. Her tone of voice enabled her to express her own frustrations at the client's noncompliance without being overtly confrontational, thereby maintaining a productive relationship. This interaction is neither extended nor intense, but it nonetheless illustrates how practitioners summon a range of emotions to influence behaviour.

Whilst there has been a further shift towards engagement with 'things' at Elizabeth Street since $T R$, the myriad challenges faced by clients means that practitioners must constantly be prepared to undertake emotional labour:

You could have one person who's in crisis which turns your whole day upside down, and everything falls into disarray. A lot of the time, the job is about crisis management. You plan your day as much as you can, but at any point you might have to change. Even though you try and structure your day, every day is different and everything can change at the drop of a hat. (Vicky, PSO)

The use of the term 'crisis' typically refers to a sudden change in clients' circumstances, whether material or psychological. Such instances often demand displays of emotion that are both extended and intensive (Morris and Feldman, 1996). Here, recourse to 'genuine expression' (Kadowaki, 2015) of emotions means that practitioners prioritise clients over the CRC's requirements for timely recording:

On the occasion that I've had people in crisis, I've been in there for two hours. But the notes on nDelius [probation's case management system] suggest that I've only been in 
there five minutes because I don't have time to record it. I've just not got the time. I'm massively, massively behind on contacts with my entire caseload. (Marie, PSO)

That Marie is inclined to forgo the administrative side of her role to perform emotional labour with clients in need demonstrates how staff consider affective displays of emotion to be the 'professional' course of action (Evetts, 2013). This work is essential to preventing harm:

One day, when I was expecting to have an admin day, empty diary, I had a crisis day because [a client] was suicidal. That took three hours, three hours out of my day...You can't cut people off when they're in crisis. (Rhonda, PSO)

A willingness to react to crises, to drop everything to ensure a client's wellbeing, demonstrates how practitioners prioritise working with 'people' over working with 'things' (Hochschild, 2012):

I always bought into a probation service that could make change and, you know, change people's lives for the better; now, I feel like we can do that still, but at a cost to the service because there's so much target work to do. I want to spend my time...with service users, and I can't say, 'well, actually, I can't spend that time with you'. So, I'll let my admin work suffer so that I can spend time with the service user. (Vicky, PSO)

This epitomises how organizational professionalism is enacted within probation. For the organization, emotional labour can prove crucial to preventing (further) harm, although this can detract from the computer-based recording on which the $\mathrm{CRC}$ depends for payment. For practitioners, probation values serve to self-motivate staff to provide a professional service; however, the resultant pressures on staff who fall behind on administrative work can lead to emotional exhaustion (Hochschild, 2012).

\subsection{Stress, strain and sickness in probation}

HM Prison and Probation Service publish regular workforce statistics bulletins which detail staff sickness within the NPS (MoJ, 2019). CRCs are not obliged to publish data on staffing; however, HMI Probation (2017) have reported on how sickness absence is prevalent 
within CRCs (see also Walker et al., 2019). Indeed, staff perceived sickness to be a significant issue at Elizabeth Street:

...we're not supported about the caseload; people [are] leaving in droves, getting ill. I mean, there's always been sickness in probation - that's another story - but this is completely through stress, I would say. (Rhonda, PSO)

Rhonda's comment indicates that high levels of sickness predate the $T R$ reforms. A study by the National Audit Office (2006), for example, analysed the financial impact of staff sickness on the NPS during the period 2004/05. The report supports her claim, highlighting how sickness was higher in the probation service than comparable public sector occupations and acknowledging the links between stress and excessive workloads for those who remain:

People are off work for quite a long time with work-related stress, anxiety, and that's hard when you're in a small team carrying high caseloads. That negative impact's not nice, and it can have a physical impact on you, getting tired and demotivated. (Trudy, PSO)

Westaby et al. (2016: 114) have challenged the mutual exclusivity of personal and professional environments for probation practitioners via the notion of 'spillover', which "posits that one's professional life can affect one's personal life." This is based on Greenhaus and Beutell's (1985) work-family conflict model, which argues that such boundaries can be undermined by 'time-based', 'behaviour-based', and 'strain-based' conflicts. 'Time-based' conflict relates to an inability to complete work during office hours, which means that it is taken home:

You are quite literally married to this role, I would say. I work late at night at home and everything to get reports done. I know there's always been targets and deadlines and everything, but everything now has become time-scaled. (Mo, PSO)

'Behaviour-based' conflict manifests when the behaviours expected of a professional role are unwelcome in one's personal life. Here, the emotional toll of working with clients with a history of violence can impact upon personal relationships: 
...a lot of our work is domestic violence, which impacts on your life: the trauma you get from reading reports can be significant. It can make you be untrustful [sic] towards men, as a woman; it makes you hyper-vigilant to certain behaviours in the opposite sex...You are exposed to vicarious trauma, secondary trauma...because some of it can be really, really nasty. (Mo, PSO)

Hence, 'strain-based conflict' occurs when practitioners feel unable to 'switch off':

How do you measure the fact that you had a difficult situation the day before and you didn't sleep well, which affects your performance? How do you measure that? You had a case that was already a risky situation, you know, risk of harm the day before. You cannot go home and go to sleep and forget about it. You carry it; you cannot switch off completely. (Leon, PSO)

Camilla (PSO) noted that 'strain-based conflict' can result from the demands placed upon staff from the CRC:

...we're just expected to do everything and more, but with less. It's always from the hierarchy, from the top down: 'you've got laptops, you've got phones: just do it'. But it's not as simple as that. There's always cracks somewhere; just keep sticking the plaster back over it.

Such pressures are not always imposed, but are also habitual. As Camilla continued:

I'm a sucker to myself, really, because if something needs to be done then I'll say, 'yeah, I'll do that'. I like the trickier ones, the more challenging ones: I like taking them.

Her comments highlight how organizational professionalism operates in a probation context. Practitioners' good intentions, derived from their values, can be mobilised to justify further increases to their workload (Evetts, 2013). Accordingly, some staff have revised their expectations of work, which hints at 'emotive dissonance' (Hochschild, 2012):

You have to lose your desire to get to know this person over a period time so you can write that something up... What I try to do is spend time with somebody, gradually 
getting to know them, but that's not what the service wants: the service wants something. (Fizz, PO)

Fizz's response hints at a measure of alienation from probation work. She rationalised a reduced standard of service as necessary for self-preservation: investing oneself in the client and engaging in emotional labour is prerequisite to good practice, but can be detrimental to meeting performance targets. The 'something' that the service wants (i.e. timely recording) can constrain practitioners' ability and, ultimately, their willingness to prioritise relationships with clients. In other words, staff must become dissociated from 'genuine expression' (Kadowaki, 2015) of emotion and engage in 'surface acting' - which, in the long, has the potential to produce strain (Hochschild, 2012). The next section, therefore, shows how such pressures can result in sickness.

\subsubsection{Case Study: Will, PSO}

A PSO with eleven years' experience in the role, Will spoke openly of a recent stressrelated absence. He argued that increases to his workload after $T R$, particularly in terms of administrative work, contributed to sickness:

I had two and a half months off this year, completely related to stress because of the volume of work and additional tasks that we never had to do in our role before, which is administrative kind of stuff and not being able, no matter how hard I work, to tick every box.

Will's experience of probation corresponds with Evetts's (2013) notion of organizational professionalism. On the one hand, he is motivated by working with people, conforming to the probation service's people-oriented ideology of service:

...the interviewing side of it, as it stands now, the interviewing side of it is the side I enjoy: working with people.

On the other hand, the expectation that targets will be met represents how autonomy over work is subservient to the targets on which the CRC depends for payment. Whilst acknowledging 
that these targets are not exclusive to $T R$, Will linked their escalation since the reforms to his time off sick:

Historically, there's always been targets associated with the work, but it was much looser. For example, there was always a deadline for the completion of an initial sentence plan - which used to be five weeks; it's three weeks now - but it wasn't financially motivated. There [are] targets associated with certain aspects of the job, [but] the vast majority of the targets weren't an issue.

Will no longer recognises the job: he wants to spend time with clients and engage with them in an emotional capacity, but the financial pressures imposed upon the CRC by the state mean that their recording requirements must take precedence:

If I haven't got the time to sit with people like [I] used to have, or talk to them on the phone, then I feel like I'm just ticking boxes, going through the motions. I'm not getting to know these people as well as I used to do. I understand the risk that they pose and managing those risks; but if I understood the person, if I had the opportunity to get to know them more - spend more time with them in supervision, for example, or do home visits - then I would have a better understanding... of managing their risk long-term, or even short-term. (my emphasis)

Despite Will's preference for 'genuine expression' (Kadowaki, 2015) of emotion, he has become resigned to 'surface acting' (Hochschild, 2012), 'going through the motions' so as to meet organizational requirements. How he understands his job, and thus his professional identity, has changed to become more focused on what the $\mathrm{CRC}$ requires as opposed to what, in his view, the client needs:

I suppose, having had time off work because of the stress, what I expect of myself has changed, I think. I think that's a good way of putting it. I always expect a lot of myself: I like to do a good job, a thorough job...I think coming back to work, coming to the realisation that I have to do things differently for my own well-being beyond anyone else, has changed what I expect of the job. (my emphasis) 
This corresponds with Westaby's (2010) study of immigration solicitors working within the field of asylum law, which found that some relied upon 'surface acting' to convey expected emotional display with clients. Will's client-centred values remain, but he recognises that he cannot act upon them in the desired fashion.

Will's experience resonates with Hochschild's (2012: 21) observation that, "[w]hen a speed-up of the human assembly line makes "genuine" personal service harder to deliver, the worker may withdraw emotional labor and offer instead a thin crust of display." His professional identity has thus adapted to the demands of an environment in which targets have accrued greater (financial) significance. In the long-run, this could be problematic for a service that has historically been premised on humanitarian endeavour:

...if people are not happy with the service, they won't do it with their heart; they'll do it mechanistically. That's not what we want; what we want is people who work here because they want to and they've got the right values to do it, to achieve what the service user needs. (Ashley, Senior Manager; my emphasis)

Ashley's comment recognises the importance to the CRC of staff who are guided by the 'right values'; but, as Will testified, enacting such ideals can lead to 'emotional exhaustion' and, ultimately, 'emotional dissonance' (Hochschild, 2012). A desire to work with people and give the client a professional service can, paradoxically, expose staff to enhanced stress and strain. In this sense, probation work conforms to organizational professionalism (Evetts, 2013), manifest in the difficulties of balancing emotional labour with clients and the administrative duties expected by the CRC.

\subsection{Conclusion}

Against the backdrop of a probation office remade according to the logic of competition and profit, this paper has demonstrated the endurance of a shared ideology of service at Elizabeth Street. That staff want to work with people is a precondition of probation work, contributing to professional identity premised on helping clients to engender change. And yet, the administrative actions required of staff by the $\mathrm{CRC}$, which are set by the state as conditions of payment, are typically achieved via engagement with 'things' (Hochschild, 2012) - that is, the information technologies that are fundamental to late-modern probation practice. Opportunities to perform (face-to-face) emotional labour with clients may have diminished; 
but when they are undergoing a crisis, the length and intensity of such interactions reflects cultural understandings of 'professional' conduct.

The challenges of balancing a client-centred ideology of service with an adherence to performance targets are by no means unique to $T R$, but rather, have been exacerbated by the reforms, rendering practitioners more vulnerable to stress and sickness (HMI Probation, 2017; Walker et al., 2019). Organizational professionalism (Evetts, 2013) can be utilised to make sense of these conflicts: the CRC can expect a professional service from practitioners when working with clients, even as individual workloads increase. A potential consequence of these tensions, as evidenced by Will (PSO), is that the people-oriented values that render a probation practitioner 'the right kind of person for the job' can also enhance the likelihood of emotional exhaustion and, eventually, 'emotional dissonance' (Hochschild, 2012).

As such, probation providers, whether publicly- or privately-led, could do more to be mindful of practitioners' emotional wellbeing and to ensure that are supported in their work (HMI Probation, 2019). Administratively, the provision of extra resources could enable more face-to-face engagement with clients; professionally, more training could educate staff on how to better handle emotionally challenging situations; and personally, access to counselling services could help to mitigate the impact of 'vicarious trauma' (Mo, PSO).

\section{Funding}

This research did not receive any specific grant from funding agencies in the public, commercial, or not-for-profit sectors.

\section{References}

Annison, J., Eadie, T. and Knight, C., 2008. People first: Probation officer perspectives on probation work. Probation Journal, 55(3): 259-271.

Burke, L., Millings, M. and Robinson, G., 2017. Probation migration(s): Examining occupational culture in a turbulent field. Criminology \& Criminal Justice, 17(2): 192-208.

Carr-Saunders, A.M. and Wilson, P.A., 1933. The Professions. Oxford: Oxford University.

Cohen, S., 1985. Visions of Social Control. Cambridge: Polity. 
Deering, J., 2010. Attitudes and beliefs of trainee probation officers: A 'new breed'? Probation Journal, 57(1): 9-26.

Deering, J. and Feilzer, M.Y., 2015. Privatising Probation: Is Transforming Rehabilitation the end of the probation ideal? Bristol: Policy.

Evetts, J., 2013. Professionalism: Value and ideology. Current Sociological Review, 61(5-6): 778-796.

Fournier, V., 1999. The appeal to 'professionalism' as a disciplinary mechanism. Social Review, 47(2): 280-307.

Freidson, E., 1970. Profession of Medicine: A Study of the Sociology of Applied Knowledge. New York, NY: Dodd, Mead \& Company.

Greenhaus, J.H. and Beutell, N.J., 1985. Sources of conflict between work and family roles. The Academy of Management Review, 10(1): 76-88.

Hammersley, M. and Atkinson, P., 2007. Ethnography: Principles in Practice. Third Edition. London: Routledge.

Hochschild, A., 2012. The Managed Heart: Commercialization of Human Feeling. Los Angeles, CA: University of California.

House of Commons Justice Committee, 2017. Oral Evidence: Transforming Rehabilitation, Tuesday 21 March 2017. London: House of Commons.

HMI Probation, 2017. 2017 Annual Report. Manchester: HM Inspectorate of Probation.

HMI Probation, 2018. Probation Supply Chains: A Thematic Inspection by HM Inspectorate of Probation. Manchester: HM Inspectorate of Probation.

HMI Probation, 2019. Report of the Chief Inspector. Manchester: HM Inspectorate of Probation.

Kadowaki, J., 2015. Maintaining professionalism: emotional labor among lawyers as client advisors. International Journal of the Legal Profession, 22(3): 323-345.

Kemshall, H. and Wood, J., 2007. High-risk offenders and public protection. In: Gelsthorpe, L. and Morgan, R. (eds.) Handbook of Probation. Cullompton: Willan.

Kirton, G. and Guillaume, C., 2015. Employment Relations and Working Conditions in Probation after Transforming Rehabilitation: With a special focus on gender and union effects. London: School of Business and Management, Queen Mary University London. 
Knight, C., 2007. Why choose the Probation Service? British Journal of Community Justice, 5(2): 55-69.

Maruna, S. 2001. Making Good: How Ex-Convicts Reform and Rebuild their Lives. Washington, DC: American Psychological Association.

Mawby, R.C. and Worrall, A., 2013. Doing Probation Work: Identity in a Criminal Justice Occupation. London: Routledge.

May, T. and Annison, J., 1998. The de-professionalization of probation officers. In: Abbott, P. and Meerabeau, L. (eds.) The Sociology of the Caring Professions. Second Edition. London: UCL.

McNeill, F., 2013. Transforming Rehabilitation: evidence, values and ideology. British Journal of Community Justice, 11(2-3): 83-86.

McWilliams, W., 1983. The Mission to the English Police Court 1876-1936. The Howard Journal, 22: 129-147.

McWilliams, W., 1985. The Mission transformed: Professionalisation of probation between the Wars. The Howard Journal, 24(4): 257-274.

McWilliams, W., 1987. Probation, pragmatism and policy. The Howard Journal, 26(2): 97121.

Ministry of Justice, 2010. Breaking the Cycle: Effective Punishment, Rehabilitation and Sentencing of Offenders. London: HMSO.

Ministry of Justice, 2013a. Transforming Rehabilitation: A Strategy for Reform. London: HMSO.

Ministry of Justice, 2013b. Punishment and Reform: Effective Probation Services. Summary of Consultation Responses. London: Ministry of Justice.

Ministry of Justice, 2019. Her Majesty's Prison and Probation Service (HMPPS) Workforce Statistics Bulletin, as at 31 December 2018. London: Ministry of Justice.

Morris, J.A. and Feldman, D.C., 1996. The dimensions, antecedents, and consequences of emotional labor. The Academy of Management Review, 21(4): 986-1010.

National Audit Office, 2006. The Management of Staff Sickness Absence in the National Probation Service. London: Stationery Office. 
National Audit Office, 2016. Transforming Rehabilitation. London: House of Commons.

National Audit Office, 2019. Transforming Rehabilitation: Progress Review. London: Home Office.

Nellis, M., 1995. Probation values for the 1990s. Howard Journal of Criminal Justice, 34(1): $19-44$.

Phillips, J., 2011. Target, audit and risk assessment cultures in the probation service. European Journal of Probation, 3(3): 108-22.

Phillips, J., Westaby, C. and Fowler, A., 2016. 'It's relentless': The impact of working primarily with high-risk offenders. Probation Journal, 63(2): 182-92.

Robinson, G., 2003. Technicality and indeterminacy in probation practice: A case study. British Journal of Social Work, 33: 593-610.

Robinson, G., Burke, L. and Millings, M., 2016. Criminal justice identities in transition: The case of devolved probation services in England and Wales. British Journal of Criminology, 56(1): 191-173.

Trotter, C., 2014. Working with Involuntary Clients: A Guide to Practice. Third Edition. London: Routledge.

Walker, S., Annison, J. and Beckett, S., 2019. Transforming Rehabilitation: The impact of austerity and privatisation on day-to-day working cultures and working practices in 'probation'. Probation Journal, 66(1): 113-130.

Westaby, C., 2010. 'Feeling like a sponge': The emotional labour produced by solicitors in their interactions with clients seeking asylum. International Journal of the Legal Profession, 17(2): 153-174.

Westaby, C., Phillips, J. and Fowler, A., 2016. Spillover and work-family conflict in probation practice: Managing the boundary between work and home life. European Journal of Probation, 8(3): 113-127. 